This submission to EarthArXiv is a preprint, that has already been peer-reviewed, but not published. There could be small changes between this version and a final published version of this pre-print.

\title{
Interferometric Synthetic Aperture Radar
}

Pablo J. González

Department of Life and Earth Sciences, IPNA-CSIC, La Laguna, Tenerife, Spain, and, COMET and Department of Earth, Ocean and Ecological Sciences, University of Liverpool, United Kingdom e-mail:pabloj.gonzalez@csic.es

\begin{abstract}
Interferometric Synthetic Aperture Radar (InSAR) has catapulted our ability to detect, quantify and characterize bio- and geophysical processes (e.g., aquifer dynamics, tectonic, and magmatic processes, etc.). During the last four decades, InSAR has imaged the complete Earth's surface and transformed our understanding of how Earth works. Such revolution has been underpinned by a relentless development of radar technology and processing methods and facilitated by free and open access to satellite missions' data. Although, satellite radar images represent electrical and geometrical properties of the illuminated ground surface. Here, I focus on the geometric information obtained from the phase delay (interferometric) patterns between two or more SAR images. After a brief overview of InSAR history, I review the fundamentals of the most popular interferometric methods, and present a vision on which InSAR will deliver wide and easily accessible global high-resolution processed information, highlighting future challenges to monitor and understand Earth dynamics. Finally, I encourage further work on developing new radar mission concepts, and harnessing big-data processing workflows deployed on energy efficient and fast computing infrastructure, while minimizing our environmental footprint. To achieve such ambitious goals, I argue that researchers and technicians will have to collaborate in an inclusive environment, with wide and diverse range of beneficiaries to achieve sustainability on a fast changing Earth.
\end{abstract}




\title{
Interferometric Synthetic Aperture Radar
}

\author{
Pablo J. González \\ Department of Life and Earth Sciences, IPNA-CSIC, La Laguna, Tenerife, Spain, and, COMET and \\ Department of Earth, Ocean and Ecological Sciences, University of Liverpool, United Kingdom \\ e-mail: pabloj.gonzalez@,csic.es
}

\begin{abstract}
Interferometric Synthetic Aperture Radar (InSAR) has catapulted our ability to detect, quantify and characterize bio- and geophysical processes (e.g., aquifer dynamics, tectonic, and magmatic processes, etc.). During the last four decades, InSAR has imaged the complete Earth's surface and transformed our understanding of how Earth works. Such revolution has been underpinned by a relentless development of radar technology and processing methods and facilitated by free and open access to satellite missions' data. Although, satellite radar images represent electrical and geometrical properties of the illuminated ground surface. Here, I focus on the geometric information obtained from the phase delay (interferometric) patterns between two or more SAR images. After a brief overview of InSAR history, I review the fundamentals of the most popular interferometric methods, and present a vision on which InSAR will deliver wide and easily accessible global high-resolution processed information, highlighting future challenges to monitor and understand Earth dynamics. Finally, I encourage further work on developing new radar mission concepts, and harnessing big-data processing workflows deployed on energy efficient and fast computing infrastructure, while minimizing our environmental footprint. To achieve such ambitious goals, I argue that researchers and technicians will have to collaborate in an inclusive environment, with wide and diverse range of beneficiaries to achieve sustainability on a fast changing Earth.
\end{abstract}

\section{Introduction}

Interferometric Synthetic Aperture Radar (InSAR) has been shown to be an effective technique for geodetic imaging of surface ground displacement caused by natural and anthropogenic processes, and support many practical applications (civil engineering, natural resource management, etc.). Earth's space imaging using optical sensors is opportunistic due to cloud coverage. In contrast, Earth's atmosphere is transparent to electromagnetic energy in the microwaves range. Its physical-chemical composition, presence of clouds, fog or dust, has a minor effect on microwave radiation. Active SAR sensors onboard of polar-orbiting satellites circumvent limitations of sensors using sun-light as electromagnetic radiation source. Hence, satellite radar sensors have expanded our capability to understand Earth's surface and processes.

SEASAT, in 1978, was a pioneering spaceborne satellite SAR mission. During its brief mission, it provided the first interferograms to measure surface displacements (Gabriel et al., 1989). Hence, we can consider the 1980s as the era of experimentation. Until 1991 and the ERS-1 mission, no other satellite carried a SAR sensor with InSAR capability. During the 1990s, differential InSAR facilitated revolutionary snapshots of ground displacement maps (Fig. 1). A period that concluded with the success of the Shuttle Radar Topography Mission (SRTM) in 2000. The first systematic satellite mission to map elevation of almost the entire Earth's landmasses. The 2000s saw the development of multitemporal InSAR methods. Methods that allows to extract estimates of time-dependent (mostly linear) ground deformation behavior. More recently, we have seen a large increase in the availability of SAR data, with an explosion of radar missions (e.g., Sentinel-1, COSMO-SkyMED, TerraSAR/TanDEM-X/PAZ, ALOS-2, Radarsat-2 and Radarsat Constellation Mission). New multitemporal InSAR methods recover non-linear motions beyond urban terrain land covers. Since the late 2010s, InSAR established itself as a technique reaching operability status in multiple disciplines. 


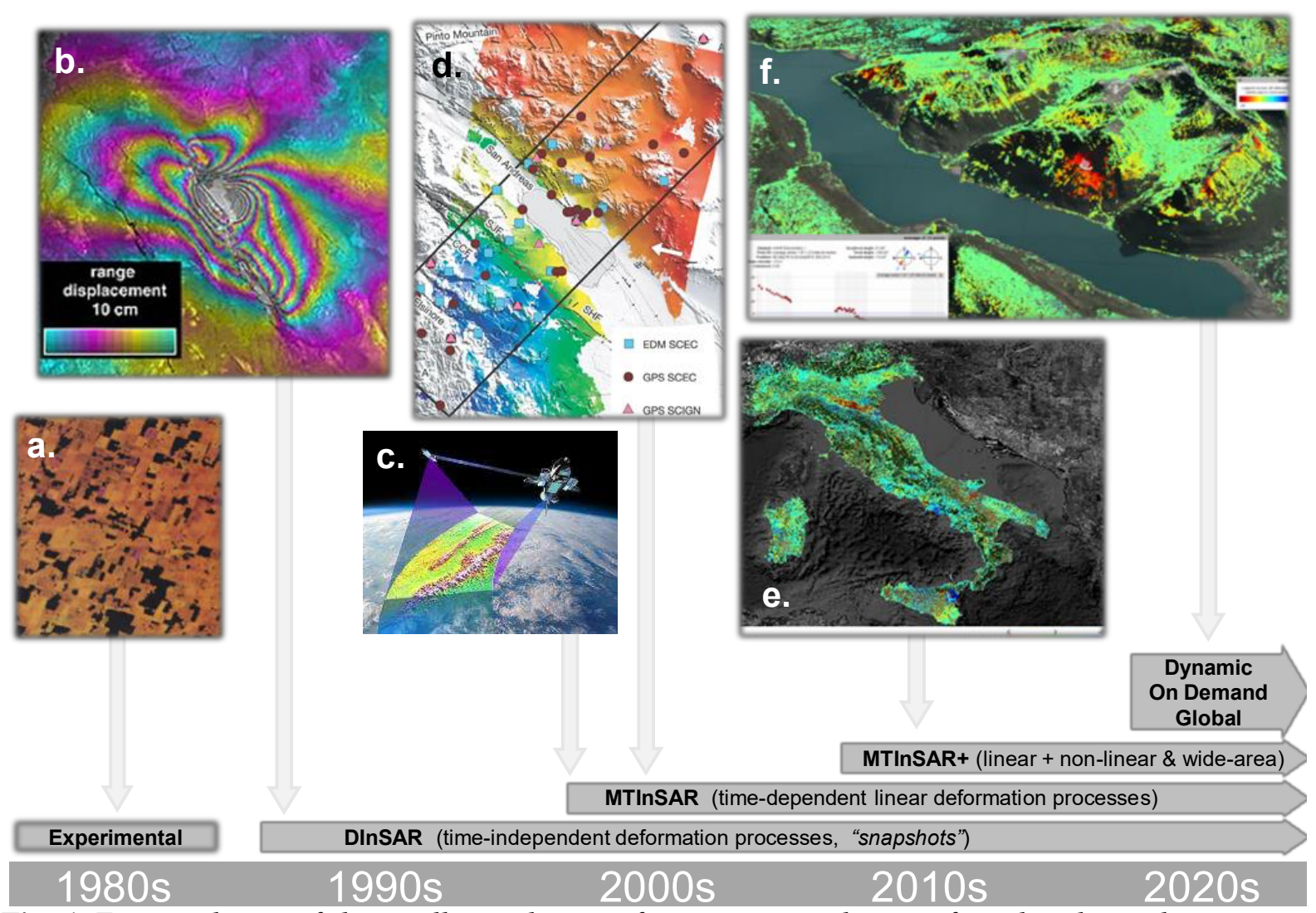

Fig. 1 Time evolution of the satellite radar interferometry over the past four decades with increasing sophistication of InSAR processing methods. From interferograms using experimental data to current widearea mapping using open and free-access Sentinel-1 data. In the near future, we expect processing methods and systems to unleash immense on-line and on-demand processing capabilities, with which to monitor and study dynamic multiscale processes globally.

The 2020 decade promises current and future systems that will live on-line, with immense on-demand processing capabilities. Over the past decade, precursors of such systems have emerged e.g., the countrywide Italy InSAR project (Ferretti et al., 2015). A trend accelerated by the launch of open, free data access Sentinel-1 mission. Sentinel-1 favored the development of many on-line platforms: from research-oriented services e.g., the COMET-LiCS project, comet.nerc.ac.uk/COMET-LiCS-portal/ (González et al., 2016; Lazecky et al., 2020); the GEP Geohazard Exploitation Platform, geohazards-tep.eu/; or the ARIA project, aria.jpl.nasa.gov/, to nation-wide operational services (e.g., $\underline{\text { insar.ngu.no/, site.tre-altamira.com/uk-insar- }}$ $\underline{\operatorname{map} /) \text {. }}$

This chapter presents a "getting started" high-level overview of satellite radar interferometry and several practical tips and reflection thoughts. Yet, it is not a comprehensive treatise on InSAR or a collection of application cases. The interested readers and practitioners are directed to review papers and textbooks such as Rosen et al. (2000), Bürgmann et al. (2000), Hansen (2001), Kampes (2006), Ketelaar (2009), Hooper et al. (2012), Moreira et al. (2013), Ferretti (2014), Sansoti et al. (2010; 2015), Simons and Rosen (2015), and Crosetto et al. (2016). Earth scientists can start reading on foundations of the physical principles of remote sensing (e.g., Rees, 2015), followed by more focused radar remote sensing textbooks such as Introduction to Microwave Remote Sensing (Woodhouse, 2006), and learning by doing relying on online resources such as e.g., these ISCE software jupyter notebooks (github.com/isce-framework/isce2docs/tree/master/Notebooks) or structured courses (e.g. eo-college.org/courses/echoes-in-space/). 


\section{Synthetic Aperture Radar: satellite sensors}

Radar Earth Observation applications rely on obtaining high resolution images with satellite sensors. SAR sensors achieve high resolution images by taking advantage of a moving platform (spacecraft). The sensor sequentially sample modulated electromagnetic pulses thousands of times per second. Hence, spacecraft motion ensures distinguishing echoes at different spatial positions, thus synthesizing a large antenna. SAR antennas overcome the intrinsic diffraction limit affecting longer-wavelength signals (Rees, 2015 p. 36). In the 1950-60s, SAR image formation principles and experimental airborne sensors were introduced (Cutrona et al., 1961; Tomayasu, 1978). A SAR sensor is side-looking to avoid left or right time arrival pulse ambiguity, causing geometric distortions (Simons and Rosen, 2015). A sensor (antenna) is coherent mainly because it emits and receives a narrowly centered electromagnetic frequency signal (wavelength, $\lambda$ ). The signal exhibits a non-random phase relationship (a sum of almost similar amplitude and frequency waves). This is the most important property of SAR antennas in regards to geodesy, transforming a SAR sensor in a ranging technique (distance satellite-target, $R$ ). Equation 1 shows the linear proportionality between range $(R)$ and phase $(\varphi)$. Hence, InSAR orbiting satellites need tight orbital control.

$$
\phi=\frac{2 \pi}{\lambda} 2 R=\frac{4 \pi}{\lambda} R
$$

SAR sensors use wavelengths (or frequency ranges) on the X-band $(2.50-3.75 \mathrm{~cm}$ or $12-8 \mathrm{GHz}), \mathrm{C}-$ band (3.75-7.5 $\mathrm{cm}$ or 8-4 GHz), and L-band ( $15-30 \mathrm{~cm}$ or 2-1 GHz). S-band $(7.5-15 \mathrm{~cm}$ or 4-2 GHz) sensors, are far less used for InSAR. In Figure 2 shows chronologically the most popular SAR satellites with interferometric capabilities. One can note that from that 24 satellites, 15 are still in operation, which illustrates increasing reliability of satellite technology. Extended missions favored the advent of a radar "golden age". An period with increased availability and reduced revisiting times (Sansosti et al., 2015).

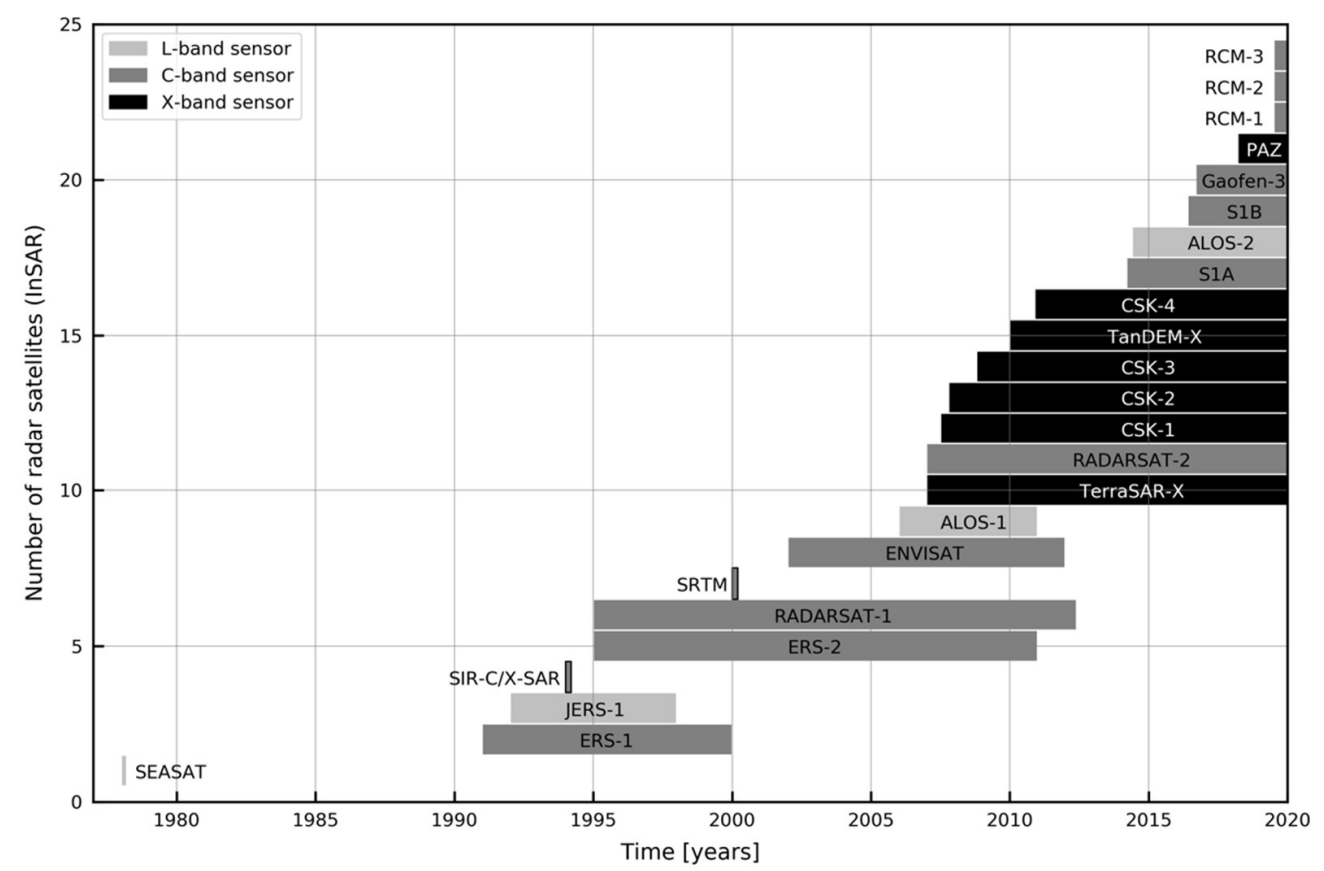

Fig. 2 SAR satellite timeline for interferometry-capable characteristics with systematic acquisitions and wide-spread usage. Different colors indicate various radar microwave frequency bands, with light gray for $L$-band; dark gray for $C$-band and black for X-band. Two missions carried multiple frequencies payloads (SIR-C/X-SAR and SRTM), both equipped with $C$ - and X-band sensors. Currently, there are 14 active InSAR-able satellites, more than ever before. 
In the next decade, we expect deployment and operation of privately-funded SAR satellites. Early examples of this are the ICEYE constellation (iceye.com), Capella Space (capellaspace.com), the optical and SAR Urthecast project (urthecast.com/optisar/), or the new low-cost S-Band UK NOVASAR-1 satellite (directory.eoportal.org/web/eoportal/satellite-missions/n/novasar-1). A combination of private and national space agencies investment will likely lead to the development new missions pursuing more frequent, wider and higher resolution Earth Observation capability (Moreira et al., 2013; Suess, 2019). Such future SAR imaging concepts will break traditional trade-off limits into the region of high resolution wide swath (HRWS) ground imaging capabilities (Fig. 3). We expect to see stationary sensors, huge constellation fleets and multi-agency missions, resulting in reducing revisit time and near-real time applications.

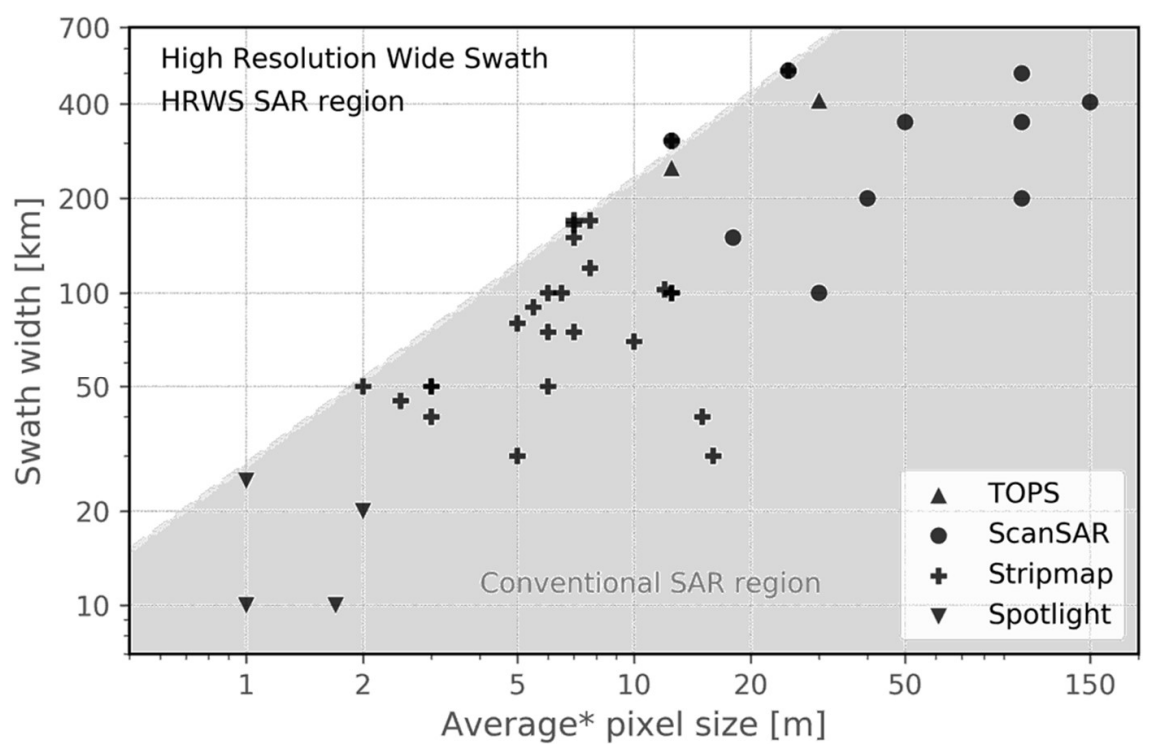

Fig. 3 Scatter plot illustrating the trade-off between swath extend (image width) and pixel resolution for existing missions using a variety of SAR acquisition modes (e.g., Simons and Rosen, 2015). Figure shows spatial resolutions and swath width achieved with spotlight, stripmap, ScanSAR, and TOPS sensors. New concepts (e.g., digital beam-forming, MIMO multiple-input multiple-output) could achieve high-resolution wide-swath SAR sensors (Moreira et al., 2013; Suess, 2019).

\section{Fundamentals of InSAR: theory and related methods}

Radar interferometry considers the two observed phases $(\phi)$ of two SAR images $(i, j)$, with respect two nearby small ground terrain area elements $(x)$. Hence, the interferometric phase $(\varphi)$ is a double-difference observation in time $(\delta t=j-i)$ and space $\left(\delta x=x_{1}-x_{2}\right)$. The spatial phase difference is most times implicit $\left(\varphi=\left[\phi^{j}\left(x_{1}\right)-\phi^{i}\left(x_{1}\right)\right]-\left[\phi^{j}\left(x_{2}\right)-\phi^{i}\left(x_{2}\right)\right]\right)$. Pixel proximity in time and space matters, because a difference larger than $2 \pi$ causes an impossible to solve phase ambiguity problem. Under the assumption of spatiotemporal small (smooth) phase differences, it is possible to unwrap the phase (e.g., Hansen, 2001; Kampes, 2006). The double difference interferometric phase $(\varphi)$ relates to three main and superimposed, contributions: a) the spatial gradient in topography $\left.\left(\varphi_{\mathrm{topo}}\right), \mathrm{b}\right)$ the spatial gradient in surface displacements occurred between temporally separated acquisitions $\left(\varphi_{\text {defo }}\right)$ and c) spatial variation in the two atmospheric conditions affecting the signal propagation at the two acquisitions $\left(\varphi_{\text {atmo }}\right)$.

$$
\varphi=\varphi_{\text {topo }}+\varphi_{\text {defo }}+\varphi_{\text {atmo }}+\left(\phi_{\text {path }}^{j}-\phi_{\text {path }}^{i}\right)
$$

a fourth phase contribution in equation 2 is more difficult to realize, but worth discussing in more detail: the target or intrapixel path phase $\left(\phi_{\text {path }}^{\mathrm{i}}\right)$ associated to each SAR image signal travel time. This phase 
contribution is very important for interferometry and variable with time, the longer the time spanned the more different is its value. It can be thought of as a finite amount of delay or virtual bouncing of the radar signal within the objects inside the pixels, i.e. an extra path added to the phase delay due to the distance satellite-target $(R)$. A change of this differential value contributes directly to $\varphi$. Smaller values with respect to the nearby pixels allow interferometry. Larger contributions might cause complete phase decorrelation, resulting in noisy (undifferentiated) patterns. The decorrelation is estimated with the interferometric coherence, i.e. a statistic on the degree of similarity of complex phase of nearby pixels. As a result, the very first condition for radar interferometry is spatial continuity. Double difference of intrapixel path radar phases must cancel out $\left(\phi_{\text {path }}^{\mathrm{j}} \approx \phi_{\text {path }}^{\mathrm{i}}\right)$.

\subsection{Topography (InSAR) vs. Surface Displacements (DInSAR)}

The terms InSAR and differential InSAR (DInSAR) often lead to confusion. We use different properties of the InSAR phase to obtain the elevation of a point (Digital Elevation Model, DEM, Figure 4a) and surface displacement (surface deformation, Figure 4b). InSAR can measure elevations with only a precision of few meters exploiting the range capabilities of the SAR signals (eq. 1); Thus, how is it possible to measure surface displacements in the order of centimeter? or vice versa.
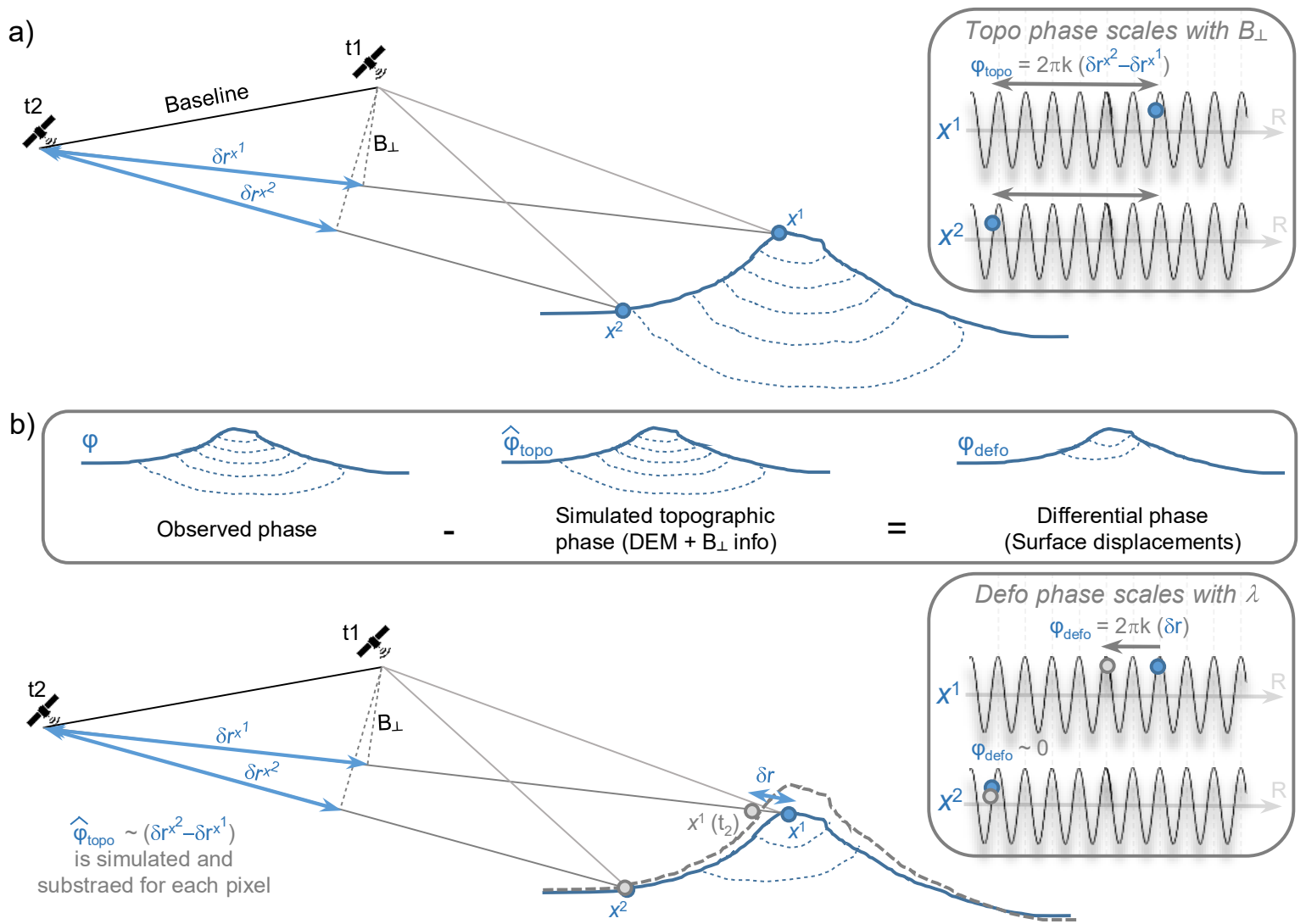

Fig. 4 Satellite radar interferometry diagrams. a) InSAR panel. Phase difference between two SAR images $\left(t_{1}\right.$ and $\left.t_{2}\right)$ is sensitive to the gradient of topography (difference in elevation between point $x_{1}$ and $x_{2}$ ). $b$ ) DInSAR panel. Differential interferometry requires to simulate the InSAR (topographic phase) based on known orbit parameters and topography of the area. The DInSAR phase is sensitive to the change in distance ( $\delta r$ ) occurred between $t_{1}$ and $t_{2}$. In contrast to the InSAR phase, the DInSAR phase scale only with the sensor wavelength $(\lambda)$. 
Let's look at the interferometric phase equation (eq. 2), assuming perfect correlation $\left(\phi_{\text {path }}^{\mathrm{j}}=\phi_{\text {path }}^{\mathrm{i}}\right.$ ), and negligible atmospheric delay contributions $\left(\varphi_{\text {atmo }} \approx 0\right)$. The interferometric phase can be rewritten in terms of range change (delay) between the two SAR images, $\varphi=4 \pi\left(R_{j}-R_{i}\right) / \lambda=4 \pi \Delta R / \lambda$. The term $\Delta R$ term is the combined physical quantity translated into measurable/observed phase change $(\varphi)$.

For constraining topography (Figure 4a), we can estimate the gradient of elevation between two nearby pixels in an interferogram $(\delta z)$. The observed phase difference between nearby pixels is proportional to the physical distance between satellite orbits $B_{\perp}$, which scales on the order of meters $\left(\varphi_{\text {topo }}=4 \pi \delta z B_{\perp} / \lambda R_{x 1}^{i} \sin \theta\right)$. As shown in equation 1, the InSAR phase is a combination of topography, surface displacement, and atmosphere. Surface displacement and atmosphere only affect the phase when using temporally separated SAR images to form an interferogram. Simultaneous, or bistatic acquisitions, which use two physical distinct antennas (e.g., SRTM or the TerraSAR-TanDEM-X global DEM missions), circumvent this ambiguity.

For surface displacement mapping (Figure $4 \mathrm{~b}$ ), we have to remove the topographic phase contribution ( $\left.\varphi_{\text {topo }}\right)$ to obtain a differential phase, $\varphi_{\text {defo }}=\varphi-\varphi_{\text {topo }}$. Removing the topographic contribution of the interferometric phase is achieved using an external DEM with a vertical accuracy proportional to the perpendicular baseline $\left(B_{\perp}\right)$. Large perpendicular baseline interferograms increase the required DEM accuracy. Thus, keeping tight orbital path tubes improve DInSAR accuracy. The differential phase is linearly proportional to the surface displacements $\delta r$ with $\varphi_{\text {defo }}=4 \pi \delta r / \lambda$. Note that the differential phase scales with the wavelength $(\lambda)$. The subtraction thus explains the dramatic difference in precision between DEM and surface deformation mapping (Fig. 4). Fig. 5 shows a high-level DInSAR processing workflow.
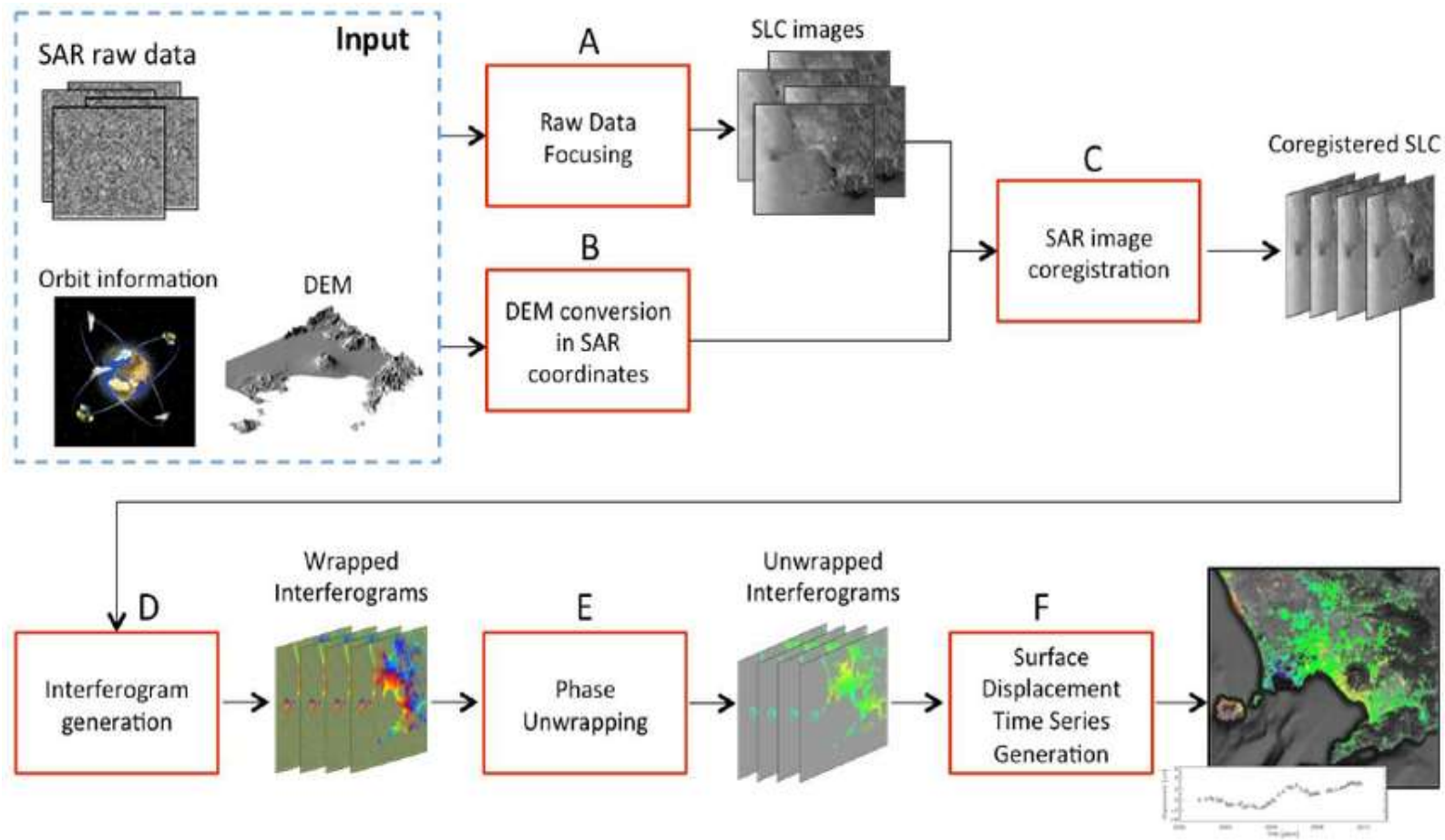

Fig. 5 Satellite radar interferometry workflow to estimate surface displacement (DInSAR). Two or more SAR images are processed using input external information (orbits and Digital Elevation Models) to obtain a precisely coregistered set of SAR images, or SAR image stack. Then interferograms (phase difference) are computed by pixel by pixel complex multiplication. Topographic, atmospheric and orbit corrections can be usually applied before or after step E. Phase unwrapping, spatio-temporal integration of phase differences results in generating surface displacement maps (DInSAR). Using large image stacks, multiple DInSAR maps are used to obtain surface displacement time series (MTInSAR). From De Luca et al., (2015). 


\subsection{Sentinel-1 TOPS interferometry}

Since April 2014, the Sentinel-1 mission designed by ESA has routinely provided frequent acquisitions (every 12 days) over larger areas than any previous SAR missions (250-400 km; Figure 6a). Due to its open data access policy, many current InSAR studies and practitioners base largely their applications on the fast and convenient access to this dataset. Therefore, it is important to clarify some processing aspects of the Sentinel-1 and how it differs from the previous mainly "stripmap" missions.

Sentinel-1 default SAR acquisition mode is the Terrain Observation by Progressive Scan (TOPS) mode. TOPS mode provides a wide coverage compared with narrower "stripmap" mode, and overcomes some limitations when compared to ScanSAR, a similar wide-area acquisition mode. In fact, ScanSAR suffers of a strong azimuthal dependence in the radar backscatterer SNR (signal-to-noise ratio) due to the pulse-burst operation and the illumination antenna pattern. In the TOPS acquisition mode, the radar beam is steered in range in each sub-swath, and it also electronically scans from backward to forward in the azimuth direction (each burst, $\sim 20 \mathrm{~km}$ ) (Figure 6a). A typical Sentinel-1 TOPS-mode image product (slice) is composed of approximately ten bursts in azimuth (subimages) for each of the three sub-swaths (Figure 6a). Sentinel-1 mission names the products acquired with TOPS mode, as IW (Interferometric Wide) and EW (Extended Wide) swath mode images. IW data is acquired in $250-\mathrm{km}$-wide swaths at $5 \mathrm{~m}$ (range) and $20 \mathrm{~m}$ (azimuth) spatial resolution, and EW data over 400-km-wide swaths at 20x40 m spatial resolution. The IW and EW modes capture three and five sub-swaths, respectively (Figure 6a).

Before the launch of Sentinel-1, the TOPS mode was experimentally exploited with the TerraSAR-X and Radarsat-2 missions and its interferometric characteristics led to the realization that, to obtain a distorsion-free phase TOPS mode interferogram, an extreme precise coregistration of the two TOPSAR images is fundamental (Prats et al., 2012). The burst scanning process and the induced azimuth variable doppler frequency result in phase distortions, or phase jumps, at the bursts' edges. To avoid significant phase discontinuities, therefore, the image pair pixels must be co-registered with a precision in the order of $1 / 1000$ th of the azimuth pixel size (i.e. $4 \mathrm{~cm}$ for Sentinel-1 TOPS-mode images, $\sim 20 \mathrm{~m}$ azimuth pixel resolution).

To avoid data gaps and due to the steering operation in range and azimuth, there are regions of data overlap within a typical Sentinel-1 data product (Figure 6b). Data overlap can occur 1) between two consecutive bursts along the same sub-swath ( $\sim .4 \mathrm{~km}$ narrow bands), 2$)$ between two adjacent sub-swaths ( $\sim 2 \mathrm{~km}$ narrow bands), and 3 ) in very small regions where multiple-overlap occurs because of the spatial coincidence of the first two cases. This means that in the overlapping regions the data is acquired with slightly different incidence angles depending on the specific sub-swaths involved and the orbit altitude. This fact might become important for geophysical applications because it will allow the extraction of redundant information about the targets' scattering-properties. This might in fact useful for the identification of persistent scatterers in multitemporal InSAR applications, and/or in the decomposition of the surface ground motion.

In addition, for TOPS interferometry, any potential azimuth misregistration between 2 TOPS images would affect the InSAR phase, as illustrated in Figure 6c. A misregistration at burst level can be represented as a rigid body displacement (shift between the red and the blue acquisition footprints). Due to variable squint angle (generated by the azimuthal radar beam steering), the "displacement" (constant misregistration offset) results in an apparent and gradual change in Line-of-sight (LoS) along the azimuth direction. This change in LoS produces a phase-trend (Figure 6c) for each burst (radar scan). If we consider that a typical Sentinel-1 TOPS image has $\sim 10$ burst per sub-swath, a full interferogram, therefore, will display multiple phase discontinuities. This problem can be empirically solved by estimating the misregistration offset using the spectral diversity technique. Refined offsets can be obtained using the phase difference between backward and forward interferogram spectra. An improved estimation has also been proposed by exploiting the larger doppler frequency difference in the bursts overlapping areas (Prats-Iraola et al., 2012). 


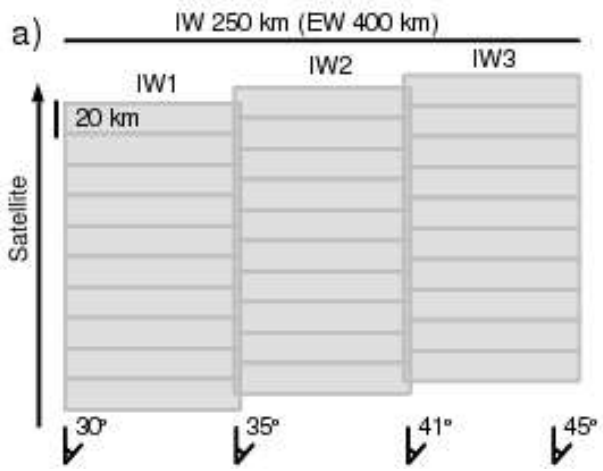

b)

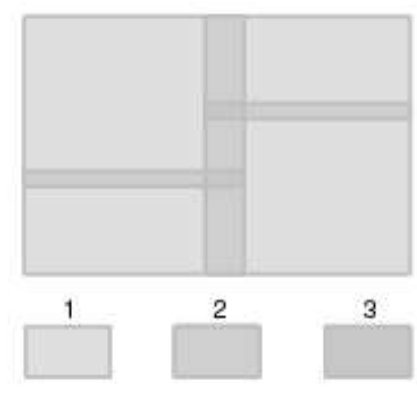

c)

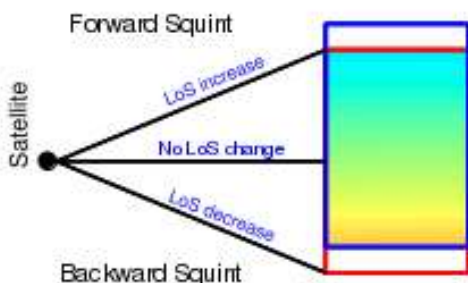

Fig. 6 a) Schematic representation of Sentinel-1 TOPS mode acquisitions. Each burst spans approx. $20 \mathrm{~km}$ in azimuth. Incidence angles varies along range/sub-swath from approx. 30 and 45 degrees. b) Illustration of an image region with data overlap between two consecutive bursts of a single sub-swath; and the adjacent sub-swaths. Please, note that in those regions multiple LoS vectors occur. This underappreciated Sentinel-1 feature should be an opportunity to develop new geophysical and processing strategies. c) Diagram showing the effects of a constant offset misregistration in the TOPS interferometric phase.

An important geophysical implication, however, arises from the TOPS misregistration in azimuth explained previously. In those cases, where the ground movement occurs along the azimuth direction and the area affected by surface displacements represents a large portion of the scene, the current proposed solutions, based on empirical data-driven coregistration, may fail. Furthermore, any significant motion in azimuth will be translated as a phase change (LoS change) (de Zan et al., 2014; Grandin et al., 2016). In this case, the LoS change is not apparent and in extreme cases the phase will be discontinuous. In Figure 7, we represent a simulated phase of a TOPS interferogram caused by a M6.5 left-lateral strike-slip earthquake along a N-S-trending fault. Note that at the burst overlap regions we the phase is discontinuous (Figure 7a). In Figure $7 \mathrm{~b}$, we show the phase contribution due to azimuth motion assuming perfect coregistration. The changes in phase sign are the response to the relative position of the illuminated ground within each burst (squint angle) and the actual ground motion (Figure 7c). For example, for the Sentinel-1 system (C-band, $5.54 \mathrm{~cm}$ wavelength) a full fringe will be produced if the ground moves $\sim 75 \mathrm{~cm}$ in the N-S direction. This problem can partially be solved using a more detailed description of the LoS vector during forward geophysical modelling (González et al., 2015). During modelling of the TOPS-INSAR observations, the LoS must vary along range, but also along azimuth (for each burst).

a)

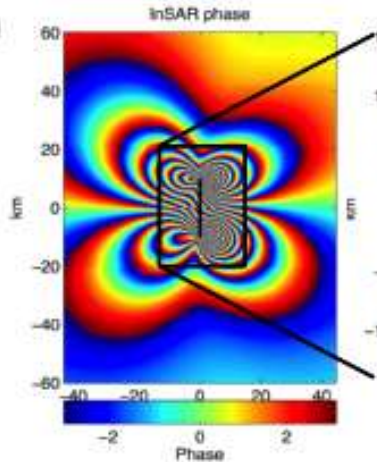

inSAR phase

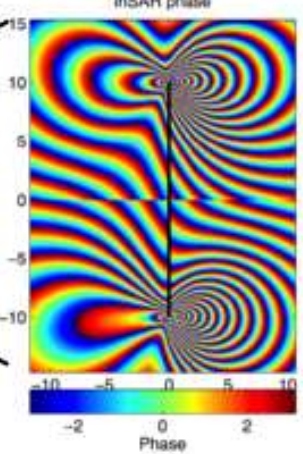

b)

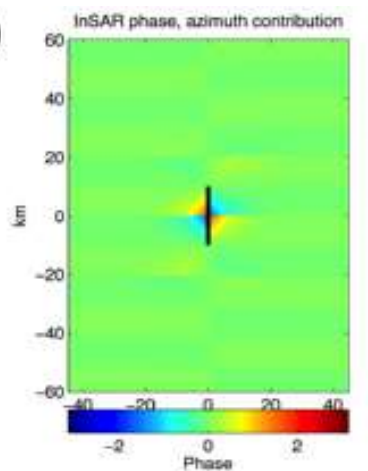

c)

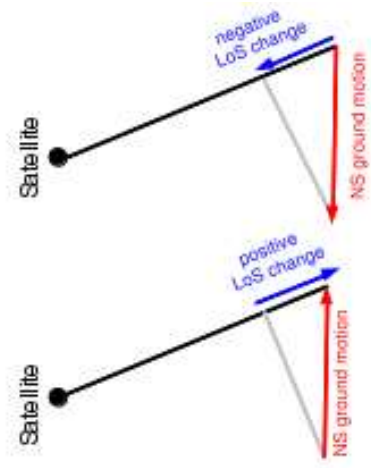

Fig. 7 a) Simulated TOPS interferometric phase caused by the coseismic ground motion due to a M6.5 leftlateral strike-slip earthquake. Please note the phase discontinuities at the burst edges. b) Phase contribution due to only azimuth component of the ground motion, assuming perfect corregistration of pixels in azimuth. c) Sketch of the LoS vector component due to azimuth steering (TOPS) on two scenarios at each side of the fault, and at the north segment of a burst. 


\subsection{Interferometry related methods}

Other related radar interferometry methods exist besides the interferometry and differential interferometry, with great potential for wide remote sensing practitioners:

- Coherence inherently tracks changes on the pair of SAR signals on an interferogram. Coherence is thus a powerful proxy for change over time, and being used to map e.g., vegetation change or disaster damage (Yun et al., 2016).

- Offset maps (or azimuth offset maps), generated via image cross-correlation, highlight surface displacements perpendicular to the range direction (along-track orbit direction) and measure complementary ground horizontal motions undetectable to DInSAR (Fialko et al., 2005). Offsets along satellite range-parallel motion component can also be estimated but at a much lower precision than interferometry (Peltzer et al., 1999).

- Bandwidth split-spectrum or spectral diversity interferograms builds upon interferometry by subdividing the signal bandwidth (Scheiber and Moreira, 2000). The core idea is to generate subimages with a narrower fraction of the full bandwidth at a cost of lower spatial resolution. Bandwidth splitting is equivalent to light color decomposition into spectral bands by a prism. Subsequently, multiple interferograms can be constructed. There are two types of split-spectrum interferograms:

- Range split-spectrum interferograms have a phase that vary linearly with respect to the subband central frequency and allows for an estimate of absolute (unbiased) range difference. Range split-spectrum interferometry has been used to estimate for example range displacements, ionospheric delays (Brcic et al., 2010; Fattahi et al., 2017), and topography (De Rauw et al., 2016).

- Azimuth split-spectrum interferograms can be formed by subdividing the aperture in azimuth into a forward and backward pair of subimages. A double difference interferogram of forward and backward pairs is sensitive to any along-track displacements (Bechor and Zebker, 2006), or ultra-precise constant azimuth misregistration offsets (Prats-Iraola et al., 2012).

- Polarimetry allows to extract structural information of radar signal bounces within the illuminated ground cells (e.g. Ulaby et al., 1990). Polarimetry is widely used for land, snow and ice, urban and ocean applications. Currently, many missions acquire images in a variety of polarizations acquisition modes: full-, dual- or quad-polarization (e.g., TerraSAR, Radarsat-2, ALOS-2, Sentinel-1).

- Polarimetric interferometry (POL-InSAR) exploits the phase diversity of single or multiple interferograms acquired at different polarizations (e.g. Hajnsek et al., 2009). The optimization of stack of coherences has led to develop multiple POL-InSAR methods to retrieve forest biogeophysical parameters.

- SAR Tomography utilizes the synthetic aperture in elevation to retrieve the vertical distribution of scatterers within a single pixel (e.g. Tebaldini and Rocca, 2011). Tomography has similar application as POL-InSAR, and has been extensively used for land classification.

\section{Multi-temporal InSAR processing methods}

Two major difficulties arise from applying InSAR for surface displacement mapping: temporal decorrelation and multiscale atmospheric effects. A simple way to reduce atmospheric effects is averaging interferograms or interferogram stacking (Sandwell and Price, 1998; Wright et al., 2001). Interferogram stacking increases the signal-to-noise ratio of time-correlated/time-independent signals. For example, we expected strong non-linear surface displacement around volcanoes, aquifers systems or active earthquakegenerating faults while atmospheric signal is expected as seasonal. However, in many instances, ground motion is more complex and time-dependent and weather patterns may correlate with topographic features (such as volcanoes). The multitemporal InSAR (MTInSAR) methods mitigate those problems. MTInSAR solves for the unmodelled residual topography, surface displacements and atmospheric phase delays components in equation 2 by relying on a set of SAR images aligned/coregistered to a reference frame. Reference frames can be a common geographical grid, a selected reference image or, more recently, a 
synthetic reflectivity reference image, based on an average predicted orbital parameters and digital elevation model information. To solve for non-linear motion, MTInSAR exploits the phase of a selected slower-decorrelating subset of pixels. There are a large number of MTInSAR analyses methods to identify good pixels' candidates (Hooper et al., 2012; Crosetto et al., 2016), with various degrees of spatialawareness.

Local or low spatial-awareness methods (Permanent of Persistent Scatterer, PS and Small Baseline, $\mathrm{SB}$ ) rely on selecting pixel candidates based on a single criterion (coherence, SAR amplitude signal dispersion, etc.) applied to a single pixel or a local, small size boxcar kernel, average window. These methods have favored temporal stability at a pixel-level due to the early discovery of pixels with long-time stable (slow-decorrelating) phase characteristics to mitigate the temporal decorrelation problem (Usai and Klees, 1999). Since the early 2000s, two main MTInSAR methods were proposed: the PS, persistent or permanent Scatterers (Ferretti et al., 2001), and the SB (or SBAS), Small Baseline methods (Berardino et al., 2002; Usai, 2003) (Figure 8). The main differences are 1) the number of reference images (one for PS, or multiple for SB methods), 2) the pixel candidate scattering properties (point-like scatterers for PS and distributed scattering for SB); and 3) the spatial averaging of pixels (multilooking) (though extensions to the SB method allow for full spatial resolution analysis, Lanari et al. (2004)). Low spatial-awareness methods usually obtain high quality results on urban terrains (Rucci et al., 2012).

Fig. 8 a) Persistent of deterministic scatterers dominate the radar response of ground targets. PS methods identify PSs as pixels with high and stable radar intensity values. PS phase values at different interferograms $\left(\phi_{x, i}\right)$ exhibit very low phase dispersion. b) Small Baselines (SB) methods exploit the temporal and/or spatial stability of the phase of group of distributed scatterers (DS).

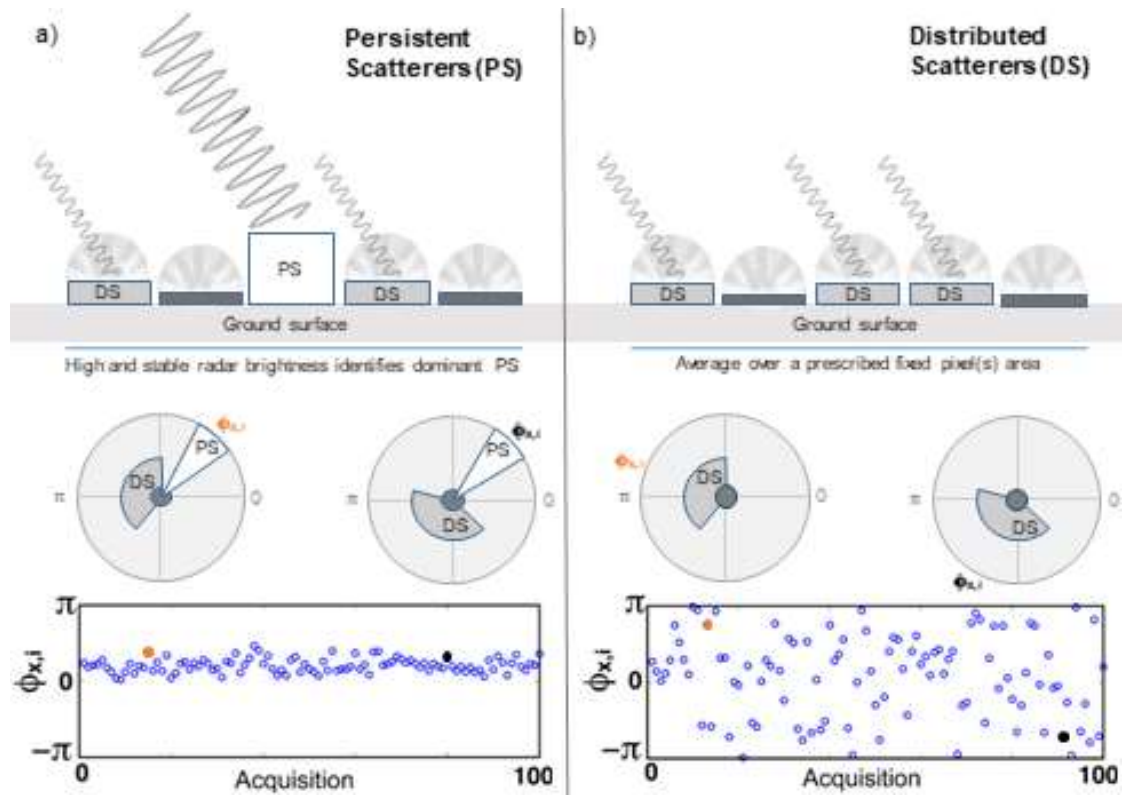

High spatial-awareness methods identify pixel candidates, or statistically homogeneous pixels SHPs, based on its statistical properties in time and in space (Ferretti et al., 2011; Parizzi and Brcic, 2011). SHPs have also been named based on the concept of close relativeness, similar but not equal, as brothers, siblings or cousins (Devanthery et al., 2014; Spaans and Hooper, 2016). The main aim of these group of methods is to simultaneously exploit persistent and distributed scatterers (Hooper, 2008), by computing all possible interferograms and exploiting its coherence matrix (Figure 9a). By doing so, high spatial-awareness and spatially adaptive approaches can extract higher quality phase information. A vector of optimum wrapped phase observations can be estimated by phase triangularity or phase-linking, on which to estimate the time series of surface displacement. (Monte Guarnieri and Tebaldini, 2008; Ferretti et al., 2011). High spatialawareness methods tend to performance better on natural terrain compared with PS methods (Hooper et al., 2004; Hooper, 2008), but have higher computational cost and trade-off with precision due to a relatively larger rate of false-positive candidate detection. 
Fig. 9 For high-spatial awareness or spatially adaptive MTInSAR methods, a) a full stack of interferograms is analysed by computing the complete coherence matrix. For each pixel, a set of statistically homogeneous pixels are identified, and then b) phase values are optimally estimated $\left(\phi_{x, i}\right)$ based on the spatio-temporal subset of SHP pixels. SHP aims to simultaneously exploit DS and PS scatterers. a)
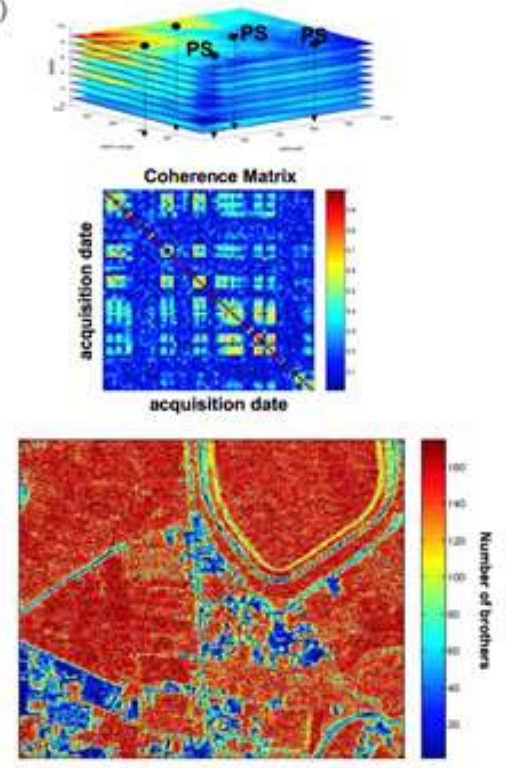

b)

Statistically Homogeneous Pixels (SHP) 


\section{InSAR challenges and future perspectives}

Although, satellite radar interferometry represents an impressive achievement of signal theory, space technology and precise data analysis to preserve the delicate phase delay information, many challenges remain to improve and widen the application of InSAR. Among these challenges, I would like to highlight the following that require actions.

Challenge \#1: Protection of the radio-electric space environment. Electromagnetic radio (microwaves) are essential in expanding global and ubiquitous internet and telecommunications resulting in high pressure on usage of the radioelectric space. GNSS satellite constellation is already suffering from radio-frequency interference ( RFI, transportation.gov/pnt). Satellite radar interferometry might also be affected by harmful interference from space- and/or ground-infrastructure. Such interferences could affect InSAR applications in urban areas, where powerful and unregulated emission points tend to proliferate. The InSAR community should exert effective lobbying at national and international governance bodies and increase awareness of interferences for radar Earth Observation missions.

Challenge \#2: Harnessing Big data. Data quality control and management are becoming very challenging tasks, due to large data volume. Single-Look Complex (SLC) level products necessary for phase interferometry are massive, e.g., a single ScanSAR ALOS-2 image can take up to $60 \mathrm{~Gb}$ of disk space). In 2004, the community echoed InSAR everywhere all the time, a claim for weekly acquisitions by 2025 (NASA, 2004). With Sentinel-1, we are eventually arriving there. However, we cannot yet process, analyze and interpret all currently acquired data and this lag will be exacerbated by future missions. We need urgent action in at least two specific directions: leveraging cost-effective processing capabilities and increasing automation. High-performance (CPU/GPU) cloud-computing infrastructure where scalable MTInSAR methods can be deployed are needed, as well as reducing processing by, for example, distributing InSAR- or data-ready products (Zebker, 2017). In addition, automation to produce informative models with machine-learning algorithms (Anantrasirichai et al., 2018) and justifying the environmental impact of data-driven models against real gains is also needed. Recent studies show large energy implications of using computationally intensive and energy-inefficient deep learning versus simple shallow classification logistic regression (Strubell et al., 2019). Exploiting all existing SAR data in full is also important (for example, SAR polarization is often underutilized) and multiple-channel polarization interferograms should be incorporated into studies of surface displacement or soil moisture (e.g., Fornaro et al., 2015; Lohman, 2019; Ansari et al., 2020).

Challenge \#3: Keep errors under the radar. Most of MTInSAR processing methods lack explicit quantification of the error budget (González and Fernández, 2011; Cao et al., 2018). New MTInSAR methods should propagate uncertainties into final estimates of surface displacements or any derived biogeophysical parameters (Knospe and Jonsson, 2010). In particular, two main sources of errors remain: the effect of stochastic multiscale atmospheric delays and phase unwrapping. Improvements on modelling $\varphi_{\text {atmo }}$ show some promise (Jolivet et al., 2011; Yu et al., 2018). However, systematic reduction or complete elimination requires further research (Bekaert et al., 2015). InSAR can be used to create atmospheric delay maps or atmospherograms (Fialko and Tymofyeyeva, 2015), which can be ingested as a weather product (Mateus et al., 2017). Yet, more experiments must be carried out before InSAR can be operationally implemented as a tool to nowcast (or forecast) atmospheric conditions. In addition, deterministic modelling of atmospheric delays should be included in MTInSAR stochastic models (Hansen, 2001; Fattahi and Amelung, 2015). In addition to the atmospheric noise, the inverted phase timeseries can potentially be biased by wrong integer numbers of cycles $(2 \pi \mathrm{rad})$ added to the interferometric phase during the twodimensional phase unwrapping, called unwrapping errors. Recently, Yunjun et al. (2019) introduced three new methods to correct or exclude phase-unwrapping errors in timeseries: 1) the bridging method connects reliable regions with minimum spanning tree bridges (for islands), 2) the phase closure method exploits the conservativeness of the integer ambiguity of interferogram triplets (for highly redundant networks), and 3) the coherence-based network modification to identify and exclude interferograms with remaining coherent phase-unwrapping errors. Ultimately, more observations will help to reduce the noise, resulting in more accurate estimation of the displacements and more reliable pixels (temporal coherence). 
Challenge \#4: Level the ground (i.e. popularization). Communicating effectively InSAR results is paramount to the popularization of the technique. Data visualization specialists have criticized the usage of poor-perception color palettes, such as the "Jet" color palette, which remains pervasive in InSAR research. To show the scale of the prevalence of the "Jet" color palette for example, note that four out of the five subpanels of Figure 1 uses the "Jet" color palette or variants of it. In addition, the tractability of InSAR results in terms of range motion, understood as movement towards the satellite or away from the satellite.

The InSAR community should transit to visualization tools that consider equity and inclusion (e.g., colorblindness). Figure 10 illustrates the impact on perception of complex deformation field (fringes) using two color palettes. Figure 10a shows the commonly used Jet palette, which includes sharp red/blue discontinuities but a blurry transition around the green-yellow color range, making it hard to identify finescale details (inset Figure 10a). in contrast, figure 10b shows the Balance palette, a colorblind-friendly option that is appropriate for wrapped phase maps. Balance is perceptually uniform, but it is divergent in lightness (Thyng et al., 2016), and enables identifying fine-scale details (inset Figure 10b). Additionally, there is a need to create interactive, inclusive, on-demand visualization tools that focus on extracting dynamics (e.g., the MSBAS method, Samsonov and d'Oreye, 2012) and rely on standarized and intuitive added-value products e.g., those generated by the NASA ARIA project or the LiCSAR-COMET portal.

Diversity and inclusion requires raising awareness of problems, and community commitment, e.g. to remove language that promotes exclusion or creates barriers. A recent example that shows hope for better is the joint and open statement signed by many in our community, on InSAR problematic terminology. The terms "master" and "slave" have traditionally used to refer to the two images forming an interferogram. Although not settled on which words should substitute them, the community insist that these terms should no longer be used (comet.nerc.ac.uk/about-comet/insar-terminology/).
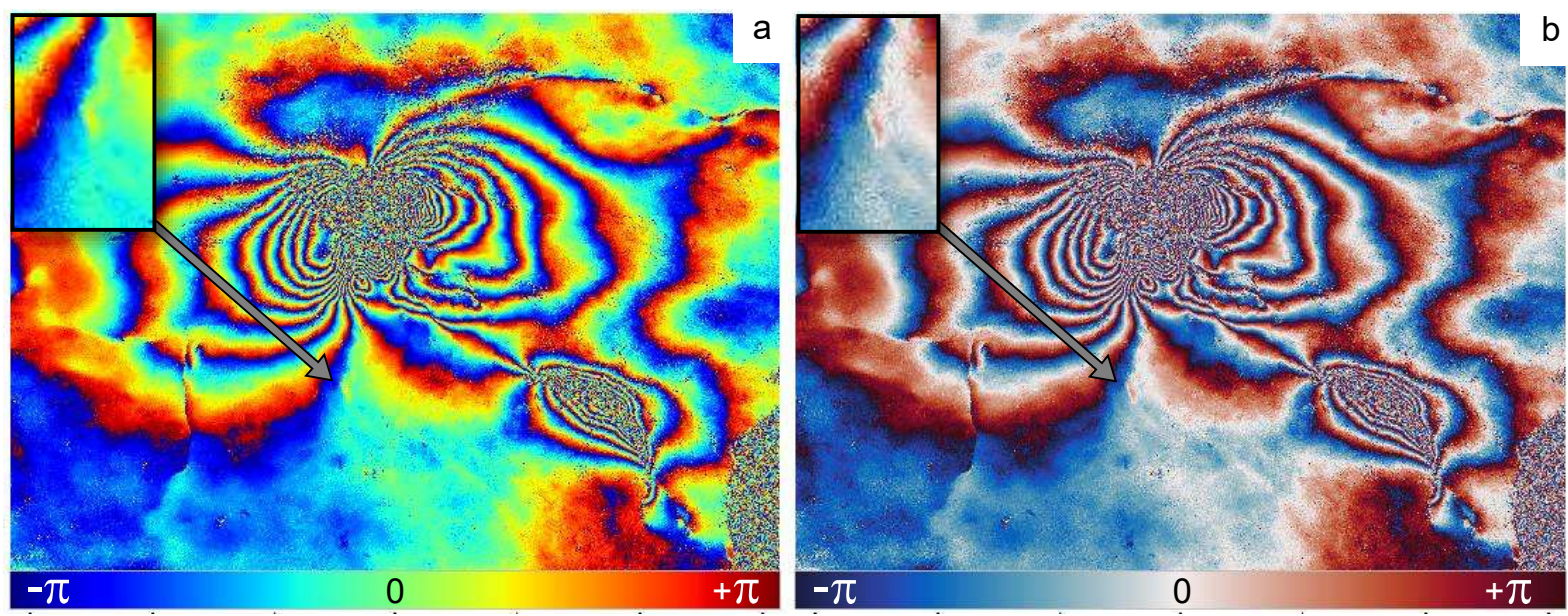

Fig. 10 Human color-perception influences inferred patterns depending on the color palette choice. The same Sentinel-1 ascending differential interferogram spanning the 2018 Mt. Etna eruption and flank motion episode is shown with different color-palettes. a) Jet palette, b) Balance palette, a perceptually uniform, color divergent and colorblind friendly palette. Note the difficulty in identifying fine-scale details with the Jet palette (inset, phase residual topography due to a recent lava flow field).

Perspectives. Over the next decade, new missions will allow us to achieve the not-long-ago unthinkable. For example, we will be able to capture the full three-dimensional surface ground deformation field, with the ESA's Harmony mission, or reduce revisit time and increase spatial and temporal resolutions (e.g., stationary-orbit satellites or large constellations). We are heading towards a future with almost ubiquitous global and daily radar information (Ferretti et al., 2015). A future that requires to maintain free and open SAR data access able to widen the InSAR data and information user base, and an essential element to grow upon a diverse and inclusive community. A future with easy access to data will likely promote 
private investments and synergies to prompt new business models with strong academic research input. Large data volumes will require to explore artificial intelligence, machine learning, compressing and lowdimensionality processing approaches to fully extract information from the wealth and richness on the SAR data (polarimetry, high-resolution, wide-area). Cheaper storage costs, on-demand, edge and distributed computing should facilitate fair reproducibility of results. However, new imaginative solutions are needed around archiving of raw and analyzed data for long-term preservation. Further research on MTInSAR processing methods, interpretation tools, and future computing power, will likely enable analyses that we cannot anticipate today. But, growth of Interferometric Synthetic Aperture Radar as a versatile and complementary remote sensing tool will certainly help to achieve more sustainable and resilient societies on the verge of fast changing planet Earth.

Acknowledgements Pablo J. González was partially supported by the NERC project Centre for the Observation and Modelling of Earthquakes, Volcanoes and Tectonics (COMET, GA/13/M/031, http://comet.nerc.ac.uk), the Spanish Ministry of Science and Innovation project COMPACT (PID2019104571RA-I00) and 2020 Leonardo Fellowship for Researchers and Cultural creators (Fundación BBVA grant). The author is grateful to Dr. Estelle Chaussard (book editor), and also in debt with the many InSAR wizards from which I learnt over the years, Tim, Andy, Petar, Sergey, Eugenio, Nicolas, and many more.

\section{References}

Anantrasirichai N, Biggs J, Albino F, Hill P, Bull D, (2018) Application of Machine Learning to Classification of Volcanic Deformation in Routinely Generated InSAR Data. J. Geophys. Res., doi: 10.1029/2018JB015911

Ansari H, De Zan, F, Parizzi, A, (2020) Study of systematic bias in measuring surface deformation with SAR interferometry. IEEE Trans. Geosci. Remote Sens., 59(2), 1285-1301

Bechor N, Zebker H. (2006) Measuring two-dimensional movements using a single InSAR pair, Geoph. Res. Lett., 33, doi: 10.1029/2006GL026883

Bekaert D, Walters R, Wright T, Hooper A, Parker D, (2015) Statistical comparison of InSAR tropospheric correction techniques, Remote Sens. Environ., 170(1):40-47, doi: 10.1016/j.rse.2015.08.035

Berardino P, Fornaro G, Lanari R, Sansosti E (2002) A new algorithm for surface deformation monitoring based on small baseline differential SAR interferograms, IEEE Trans. Geosci. Remote Sens., 40(11):2375-2383

Brcic R, Parizzi A, Eineder M, Bamler R, Meyer F, (2010) Estimation and compensation of ionospheric delay for SAR interferometry, in Proc. IEEE IGARSS, pp. 2908-2911

Bürgmann R, Rosen P, Fielding E, (2000) Synthetic aperture radar interferometry to measure Earth's surface topography and its deformation, Ann. Rev. Earth Planet. Sci., 28:169-209

Cao Y, Li Z, Wei J, Hu J, Duan M, Feng G, (2018). Stochastic modeling for time series InSAR with emphasis on atmospheric effects. Journal of Geodesy, 92(2):185-204

Crosetto M, Monserrat O, Cuevas-González M, Devanthery N, Crippa B, (2016) Persistent scatterers interferometry: a review. ISPRS J. Photogram. Remote Sens. 115:78-89, doi: 10.1016/j.isprsjprs.2015.10.011

Cutrona L, Vivian W, Leith E, Hall G, (1961) Synthetic aperture radars: A paradigm for technology evolution, IRE Trans. Military Electron., 127-131.

De Luca C, Cuccu R, Elefante S, Zinno I, Manunta M, Casola V, Rivolta G, Lanari R, Casu F, (2015) An on-demand web tool for the unsupervised retrieval of earth's surface deformation from SAR data: The P-SBAS service within the ESA G-POD environment. Remote Sens. 7: doi:10.3390/rs71115630

De Rauw D, Kervyn F, d'Oreye N, Albino F, Barbier C, (2015) Split-Band Interferometric SAR Processing Using TanDEM-X Data. In Proc. FRINGE015, Frascati, Italy, 23-27 March

De Zan F, Rocca F, (2005) Coherent processing of long time series of SAR images. In Proc. IEEE IGARSS 2005, 1987-1990. 
De Zan F, Prats-Iraola P, Scheiber R, Rucci A, (2014) Interferometry with TOPS: Coregistration and azimuth shifts, In Proc. EUSAR 2014; 10th European Conference on Synthetic Aperture Radar

Devanthery N, Crosetto M, Monserrat O, Cuevas-González M, Crippa B, (2014) An approach to persistent scatterers interferometry. Remote Sens. 6(7):6662-6679, doi: 10.3390/rs6076662

Fattahi, H., and F. Amelung (2015), InSAR bias and uncertainty due to the systematic and stochastic tropospheric delay, J. Geophys. Res. Solid Earth, 120, 8758-8773, doi:10.1002/2015JB012419.

Fattahi H, Simons M, Agram P, (2017) InSAR Time-Series Estimation of the Ionospheric Phase Delay: An Extension of the Split Range-Spectrum Technique, IEEE Trans. Geosci. Rem. Sens., 55, doi:10.1109/TGRS.2017.2718566

Ferretti A, (2014) Satellite InSAR data: Reservoir monitoring from space. EAGE publications.

Ferretti A, Colombo D, Fumagalli A, Novali F, Rucci A (2015) InSAR data for monitoring land subsidence: time to think big, Proc. IAHS, 372:331-334, doi: 10.5194/piahs-372-331-2015

Ferretti A, Fumagalli A, Novali F, Prati C, Rocca F, Rucci A, (2011) A New Algorithm for Processing Interferometric Data-Stacks: SqueeSAR. IEEE Trans. Geosci. Remote Sens., 49(9):3460-3470. doi: 10.1109/TGRS.2011.2124465

Ferretti A, Prati C, Rocca F (2001) Permanent scatterers in SAR interferometry, IEEE Trans. Geosci. Remote Sens., 39(1):8-20

Fialko Y, Sandwell D, Simons M, Rosen P, (2005) Three-dimensional deformation caused by Bam, Iran, earthquake and the origin of shallow slip deficit, Nature, 435:295-299.

Fialko Y, Tymofyeyeva E, (2015) Evaluation of Atmospheric Phase Screens by Adaptive CommonScene Stacking of Dense InSAR Data Sets, In Proc. FRINGE015, Frascati, Italy, 23-27 March http://seom.esa.int/fringe2015/page session4.php\#29p

Fornaro G, Verde S, Reale D, Pauciullo A, (2015) CAESAR: an approach based on covariance matrix decomposition to improve multibaseline-multitemporal interferometric SAR processing. IEEE Trans. Geosci. Remote Sens. 53(4):2050-2065. doi: 10.1109/TGRS.2014.2352853

Gabriel A, Goldstein R, Zebker H, (1989) Mapping small elevation changes over large areas: Differential radar interferometry, J. Geoph. Res., 94(B7):9183-9191. doi: 10.1029/JB094iB07p09183

González P J, Fernández J, (2011) Error estimation in multitemporal InSAR deformation time series, with application to Lanzarote, Canary Islands. J. Geophys. Res. 116(B10404), doi: 10.1029/2011JB008412

González P J, Bagnardi M, Hooper A J, Larsen Y, Marinkovic P, Samsonov S V, Wright, T J (2015) The 2014-2015 eruption of Fogo volcano: Geodetic modeling of Sentinel-1 TOPS interferometry. Geophys. Res. Lett., 42 (21). 9239 - 9246, doi: 10.1002/2015GL066003.

González P J, Walters R J, Hatton E L, Spaans K, McDougall A, Hooper A J, Wright T J (2016) LiCSAR: Tools for automated generation of Sentinel-1 frame interferograms, In Proc. AGU Fall Meeting, San Francisco, USA.

Grandin, R., Klein E, Métois M, and Vigny C, (2016) Three-dimensional displacement field of the 2015 Mw8.3 Illapel earthquake (Chile) from across- and along-track Sentinel-1 TOPS interferometry. Geophys. Res. Lett., 43. doi: 10.1002/2016GL067954

Hajnsek, I., Kugler, F., Lee, S. K., \& Papathanassiou, K. P. (2009). Tropical-forest-parameter estimation by means of Pol-InSAR: The INDREX-II campaign. IEEE Trans. Geosci. Remote Sens., 47(2), 481-493.

Hanssen R, (2001) Radar interferometry: data interpretation and error analysis. Kluwer

Hooper A, (2008) A multi-temporal InSAR method incorporating both persistent scatterer and small baseline approaches. Geophys Res. Lett. 35(16):96-106. doi: 10.1029/2008GL034654

Hooper A, Bekaert D, Spaans K, ArÄśkan M, (2012) Recent advances in SAR interferometry time series analysis for measuring crustal deformation. Tectonophysics 514:1-13, doi: 10.1016/j.tecto.2011.10.013

Hooper A, Zebker HA, Segall P, Kampes B (2004) A new method for measuring deformation on volcanoes and other natural terrains using InSAR persistent scatterers. Geophys. Res. Lett. 31(23):611615. doi: 10.1029/2004GL021737 
Jolivet R, Grandin R, Lasserre C, Doin MP, Peltzer G (2011) Systematic InSAR tropospheric phase delay corrections from global meteorological reanalysis data. Geophys. Res. Lett. 38:L17311. doi: 10.1029/2011GL048757

Kampes B, (2006) Radar interferometry: persistent scatterer technique. Springer.

Ketelaar V, (2009) Satellite Radar Interferometry: Subsidence Monitoring Techniques. Springer.

Knospe S, Jonsson S, (2010) Covariance estimation for dInSAR surface deformation measurements in the presence of anisotropic atmospheric noise. IEEE Trans. Geosci. Remote Sens. 48(4):2057-2065. doi: 10.1109/TGRS.2009.2033937

Lanari R, Mora O, Manunta M, Mallorquí J J, Berardino P, Sansosti E (2004) A small-baseline approach for investigating deformations on full-resolution differential SAR interferograms, IEEE Trans. Geosci. Remote Sens., 42(7):1377-1386

Lazecký M, Spaans K, González P.J., Maghsoudi Y, Morishita Y, Albino F, Elliott J, Greenall N, Hatton E, Hooper A, Juncu D, McDougall A, Walters R.J., Watson S, Weiss J, Wright T (2020) LiCSAR: An Automatic InSAR Tool for Measuring and Monitoring Tectonic and Volcanic Activity, Remote Sens., 12(15):2430. doi: $10.3390 /$ rs 12152430

Lohman R (2019) Soil moisture effects on InSAR time series in hyperarid (and not-so-arid) environments, COMET Annual Meeting 2019, 24-26 June, York, UK.

Mateus P, Catalao J, Nico G, (2017) Sentinel-1 interferometric SAR mapping of precipitable water vapor over a country-spanning area. IEEE Trans. Geosci. Remote Sens., 55(5):2993- 2999, doi: 10.1109/TGRS.2017.2658342

Monte Guarnieri A, Tebaldini S, (2008) On the exploitation of target statistics for SAR interferometry applications, IEEE Trans. Geosci. Remote Sens., 46(11):3436-3443

Moreira A, et al., (2013) A tutorial on synthetic aperture radar, IEEE Geosci. Remote Magaz., doi: 10.1109/MGRS.2013.2248301

NASA (2004) InSAR Workshop summary report, https://solidearth.jpl.nasa.gov/ PDF/InSARWorkshopReport.pdf

Parizzi A, and Brcic R, (2011) Adaptive InSAR Stack Multilooking Exploiting Amplitude Statistics: A Comparison between Different Techniques and Practical Results. IEEE Trans. Geosci. Remote Sens. Lett., 8 (3): 441-445. doi:10.1109/LGRS.2010.2083631

Peltzer G, Crampe F, King G, (1999) Evidence of nonlinear elasticity of the curst from the Mw 7.6 Manyi (Tibet) earthquake, Science, 486:272-276.

Prats-Iraola P, Scheiber R, Marotti L, Wollstadt S, Reigber A, (2012) TOPS Interferometry with TerraSAR-X, IEEE Trans. Geosci. Remote Sens., 50(8):3179-3188.

Rees W, (2015) Physical principles of remote sensing. 3rd edn. Cambridge Univ. Press, Cambridge

Rosen P, et al., (2000) synthetic aperture radar interferometry, Proc. IEEE, 88:333-382.

Rucci A, Ferretti A, Monti Guarnieri A, Rocca F, (2012) Sentinel-1 SAR interferometry applications: the outlook for sub-millimeter measurements, Remote Sens. Environ. 120:156-163

Samsonov S, d'Oreye N, (2012) Multidimensional time-series analysis of ground deformation from multiple InSAR data sets applied to Virunga Volcanic Province, Geophys. J. Intern. 191(3):1095-1108. doi: 10.1111/j.1365-246X.2012.05669.x

Sandwell D, Price E J (1998) Phase gradient approach to stacking interferograms, J. Geoph. Res., 103(B12):30183-30204, doi: 10.1029/1998JB900008

Sansosti E, Casu F, Manzo M, Lanari R, (2010) Space-borne radar interferometry techniques for the generation of deformation time series: An advanced tool for Earth surface displacement analysis. Geophys. Res. Lett., 37(20), doi: 10.1029/2010GL044379

Sansosti E, Manunta M, Casu F, Bonano M, Ojha C, Marsella M, Lanari R, (2015) Radar remote sensing from space for surface deformation analysis: present and future opportunities from the new SAR sensor generation. Rendiconti Lincei, 26(1):75-84

Scheiber R, Moreira A, (2000) Coregistration of interferometric SAR images using spectral diversity, IEEE Trans. Geosci. Remote Sens., 38(5):2179-2191. 
Simons M, Rosen P (2015) Interferometric synthetic aperture radar geodesy. In: Schubert G (ed) Treatise on Geophysics, 2nd edn. Volume 3 Geodesy, Elsevier Press, 339-385

Spaans K, Hooper A, (2016) InSAR processing for volcano monitoring and other near-real time applications. J. Geophys. Res., 121(4):2947-2960, doi: 10.1002/2015JB012752

Strubell E, Ganesh A, McCallum A, (2019) Energy and Policy Considerations for Deep Learning in NLP. arXiv: 1906.02243

Suess M. (2019) ESA's future SAR mission concepts currently studied in phase 0 and phase A, In Proc. Living Planet Symposium, Milan, 13-17 May.

Tebaldini, S., \& Rocca, F. (2011). Multibaseline polarimetric SAR tomography of a boreal forest at Pand L-bands. IEEE Trans. Geosci. Remote Sens., 50(1), 232-246.

Thyng K M, Greene C, Hetland R, Zimmerle H, DiMarco S, (2016). True colors of oceanography: Guidelines for effective and accurate colormap selection. Oceanography 29(3):9-13, doi: 10.5670/oceanog. 2016.66

Tomiyasu, (1978). Tutorial review of synthetic aperture radar (SAR) with applications to imaging of the ocean surface. Proc. IEEE, 66(5):563-583, doi: 10.1109/PROC.1978.10961

Ulaby, F. T., \& Elachi, C. (1990). Radar polarimetry for geoscience applications. $a h$.

Usai S, (2003) A least squares database approach for SAR interferometric data, IEEE Trans. Geosci. Remote Sens., 41(4):753-760.

Usai S, Klees R. (1999) SAR interferometry on a very long time scale: a study of the interferometric characteristics of man-made features, IEEE Trans. Geosci. Remote Sens., 37(1):135-149.

Woodhouse I.H. (2006) Introduction to Microwave Remote Sensing. 1st Edition. CRC Press, Boca Raton, doi: 10.1201/9781315272573

Wright T, Parsons B, Fielding E, (2001) Measurement of interseismic strain accumulation across the North Anatolian Fault by satellite radar interferometry, Geoph. Res. Lett., 28, doi:10.1029/2000GL012850

Yu C, Li Z, Penna N, Crippa P, (2018). Generic atmospheric correction model for Interferometric Synthetic Aperture Radar observations. J. Geophys. Res., 123, doi: 10.1029/2017JB015305

Yun S H. et al., (2016) Recent rapid disaster response products derived from COSMO-Skymed synthetic aperture radar data. In Proc. IEEE IGARSS, doi: 10.1109/IGARSS.2016.7729533

Yunjun, Z., Fattahi, H., \& Amelung, F. (2019). Small baseline InSAR time series analysis: Unwrapping error correction and noise reduction. Comput. and Geosci., 133, 104331.

Zebker H A, (2017) User-friendly InSAR data products: fast and simple time series processing. IEEE Geosci. Remote Sens. Lett., 14(11):2122-2126. 